\title{
Cross-species analysis of protein dynamics associated with hydride and proton transfer in the catalytic cycle of the light-driven enzyme protochlorophyllide oxidoreductase.
}

\author{
Robin Hoeven, ${ }^{\ddagger}$ Samantha O. J. Hardman, ${ }^{\ddagger}$ Derren J. Heyes ${ }^{\ddagger}$ and Nigel S. Scrutton ${ }^{\ddagger *}$ \\ ${ }^{\ddagger}$ Centre for Synthetic Biology of Fine and Speciality Chemicals, Manchester Institute of \\ Biotechnology, The University of Manchester, 131 Princess Street, Manchester M1 7DN, UK
}

Purification of POR homologs. The cell pellets of the POR homologs were resuspended in cold binding buffer (500 mM NaCl, $5 \mathrm{mM}$ imidazole, 0.1\% Triton X-100, $50 \mathrm{mM}$ MOPS, $100 \mathrm{mM}$ ammonium acetate $\mathrm{pH}$ 7) and disrupted by 25 cycles of $20 \mathrm{~s}$ pulses of sonication (Bandelin, sonopuls probe VT70T/N494) at $40 \%$ intensity. A centrifugation step at 20,000 rpm for $30 \mathrm{~min}$ in a JA25:50 rotor (Beckman Coulter Inc.) followed to remove cell debris. Purification of the N-terminally tagged POR proteins was performed by binding to a $5 \mathrm{ml}$ HisTrap FF column (GE Healthcare Life Sciences) pre-equilibrated with 10 column volumes (cv) of binding buffer using an Äkta protein purification system (GE Healthcare Life Sciences). The column was washed with buffer containing $50 \mathrm{mM}$ and $100 \mathrm{mM}$ imidazole, and the final elution consisted of a gradient from $100 \mathrm{mM}$ to $500 \mathrm{mM}$ imidazole. A second purification step with a blue Sepharose 6 fast flow column (GE Healthcare Life Sciences) was performed to remove remaining contaminants. Samples were loaded onto $20 \mathrm{ml}$ column pre-equilibration with blue start buffer $(500 \mathrm{mM} \mathrm{NaCl}, 50 \mathrm{mM}$ MOPS, $100 \mathrm{mM}$ ammonium acetate $\mathrm{pH}$ 7), followed by a wash step with 10 column volumes of blue start buffer. Protein was eluted by a $\mathrm{NaCl}$ gradient, from $500 \mathrm{mM}$ to $2.5 \mathrm{M}$ using the BioLogic LP low pressure chromatography system (Bio-Rad laboratories Inc.). The fractions were visualised by SDSPAGE (12\%; Bio-Rad laboratories Inc.) and the fractions containing the purified POR protein were pooled and concentrated using a Vivaspin 20 (10 kDa MWCO; Sartorius AG). This was followed by buffer exchange into activity buffer (500 mM NaCl, $50 \mathrm{mM}$ MOPS, $100 \mathrm{mM}$ ammonium acetate $\mathrm{pH}$ 7) using a CentriPure P100 column (Generon Ltd.) to remove salt. Finally, the protein samples were concentrated to a typical volume of around $4 \mathrm{ml}$ with a Vivaspin 20 (10 kDa MWCO; Sartorius AG), aliquoted in smaller volumes and flash frozen in liquid nitrogen, to be stored at $-80^{\circ} \mathrm{C}$. 
Table S1. The rates of hydride transfer for the cyanobacterial POR homologs at $4^{\circ} \mathrm{C}$ obtained by fitting to a bi-exponential equation. The data were fitted to a bi-exponential equation, where the first rate constant $\left(k_{1}\right)$ was fixed at $3 \times 10^{7} \mathrm{~s}^{-1}$ and the calculated rate constants for hydride transfer $\left(k_{2}\right)$ and their respective amplitudes are shown.

\begin{tabular}{ll|l|l|l}
\multicolumn{2}{c}{$\mathbf{0} \%$ glycerol } & 60 \% glycerol \\
\cline { 2 - 5 } & $\begin{array}{l}\boldsymbol{k}_{\text {hydride }} \\
\left(\mathbf{s}^{-1}, \mathbf{x ~ 1 0} \mathbf{1 5}\right)\end{array}$ & Amplitude (Abs) & $\begin{array}{l}\boldsymbol{k}_{\text {hydride }} \\
\left(\mathbf{s}^{-1}, \mathbf{x ~ 1 0} \mathbf{5}\right)\end{array}$ & \\
\hline L. majuscula & $11.1 \pm 0.4$ & $0.149 \pm 0.013 \times 10^{-1}$ & $7.6 \pm 0.4$ & $0.089 \pm 0.023$ \\
\hline N. punctiforme & $9.1 \pm 0.9$ & $0.083 \pm 0.017$ & $7.1 \pm 0.7$ & $0.081 \pm 0.058$ \\
\hline T.elongatus & $9.9 \pm 0.3$ & $0.072 \pm 0.023$ & $9.0 \pm 0.5$ & $0.069 \pm 0.009$ \\
\hline
\end{tabular}

Table S2. Rates of proton transfer at different solvent viscosities for all POR homologs. The data were fitted to a single exponential equation and the resulting rate constants at each of the solventviscosities are shown for POR from cyanobacteria (red), algae (gold), bryophyte (green), gymnosperm (purple) and angiosperms (blue).

\begin{tabular}{l|l|l|l|l|} 
& L. majuscula & N. punctiforme & C. reinhardtii & C. merolae \\
\cline { 2 - 5 } $\mathbf{n}(\mathbf{c P})$ & $\boldsymbol{k}_{\text {proton }}\left(\mathbf{s}^{-\mathbf{1}} \mathbf{\mathbf { x 1 0 }}\right)$ & $\boldsymbol{k}_{\text {proton }}\left(\mathbf{s}^{-\mathbf{1}} \mathbf{\mathbf { x 1 0 }}\right)$ & $\boldsymbol{k}_{\text {proton }}\left(\mathbf{s}^{-\mathbf{1}} \mathbf{\mathbf { x 1 0 }}\right)$ & $\boldsymbol{k}_{\text {proton }}\left(\mathbf{s}^{\mathbf{- 1}} \mathbf{\mathbf { x 1 0 }} \mathbf{\mathbf { 5 }}\right)$ \\
\hline $\mathbf{0 . 9 0}$ & $9.97 \pm 1.5$ & 3.08 & $2.35 \pm 0.3$ & $2.02 \pm 0.2$ \\
\hline $\mathbf{1 . 1 7}$ & $8.10 \pm 1.2$ & 2.94 & $2.01 \pm 0.3$ & $1.95 \pm 0.2$ \\
\hline $\mathbf{1 . 5 6}$ & $7.41 \pm 0.7$ & 2.23 & $1.95 \pm 0.2$ & $1.91 \pm 0.3$ \\
\hline $\mathbf{2 . 4 9}$ & $5.76 \pm 0.1$ & 2.07 & $1.98 \pm 0.4$ & $1.89 \pm 0.2$ \\
\hline $\mathbf{3 . 2 2}$ & $4.72 \pm 0.3$ & 1.48 & $1.99 \pm 0.3$ & $1.85 \pm 0.3$ \\
\hline $\mathbf{5 . 1 1}$ & $2.75 \pm 0.2$ & 0.63 & $2.05 \pm 0.2$ & $1.96 \pm 0.2$ \\
\hline $\mathbf{7 . 4 5}$ & $1.59 \pm 0.04$ & 0.57 & $1.65 \pm 0.2$ & $1.89 \pm 0.3$ \\
\hline $\mathbf{9 . 0}$ & $1.22 \pm 0.1$ & 0.57 & $1.65 \pm 0.1$ & $1.75 \pm 0.1$ \\
\hline
\end{tabular}

\begin{tabular}{|c|c|c|c|c|c|}
\hline & P. patens & P. mugo & D. carota & N. tabacum & Z. mays \\
\hline$\eta(c P)$ & $\begin{array}{l}\boldsymbol{k}_{\text {proton }} \\
\left.\mathbf{x 1 0}^{5}\right)\end{array}$ & $\begin{array}{l}k_{\text {proton }} \\
\left.\mathbf{x 1 0}^{5}\right)\end{array} \quad\left(\mathrm{s}^{-1}\right.$, & $\begin{array}{l}k_{\text {proton }} \\
\left.\mathbf{x 1 0}^{5}\right)\end{array}$ & $\begin{array}{l}k_{\text {proton }} \\
\left.\mathrm{x10}^{5}\right)\end{array}$ & $\begin{array}{l}k_{\text {proton }} \\
\left.\mathbf{x 1 0}^{5}\right)\end{array}$ \\
\hline 0.9 & $2.41 \pm 0.2$ & $2.25 \pm 0.1$ & $1.95 \pm 0.1$ & $4.08 \pm 0.3$ & $1.76 \pm 0.1$ \\
\hline 1.17 & $2.34 \pm 0.1$ & $2.43 \pm 0.1$ & $2.01 \pm 0.2$ & $3.92 \pm 0.2$ & $1.94 \pm 0.04$ \\
\hline 1.56 & $2.54 \pm 0.1$ & $2.44 \pm 0.1$ & $2.06 \pm 0.2$ & $3.93 \pm 0.2$ & $1.89 \pm 0.1$ \\
\hline 2.49 & $2.73 \pm 0.1$ & $2.61 \pm 0.1$ & $2.30 \pm 0.3$ & $4.16 \pm 0.2$ & $2.01 \pm 0.1$ \\
\hline 3.22 & $2.24 \pm 0.1$ & $2.10 \pm 0.2$ & $2.24 \pm 0.2$ & $3.76 \pm 0.3$ & $1.65 \pm 0.1$ \\
\hline 5.11 & $2.48 \pm 0.1$ & $2.15 \pm 0.1$ & $2.36 \pm 0.3$ & $3.30 \pm 0.1$ & $1.53 \pm 0.1$ \\
\hline 7.45 & $2.19 \pm 0.1$ & $2.08 \pm 0.3$ & $2.36 \pm 0.3$ & $3.78 \pm 0.4$ & $1.47 \pm 0.1$ \\
\hline 9.0 & $2.22 \pm 0.2$ & $1.98 \pm 0.1$ & $2.11 \pm 0.3$ & $3.78 \pm 0.2$ & $1.38 \pm 0.1$ \\
\hline
\end{tabular}


Table S3. The thermodynamic parameters derived from fitting the data in figure 5.6. $\Delta G^{\ddagger}$ was calculated by using equation S2 and a temperature of $298 \mathrm{~K}$.

\begin{tabular}{ll|l|l} 
& N. punctiforme & C. reinhardtii & Z. mays \\
\cline { 2 - 4 } $\boldsymbol{\Delta} \boldsymbol{H}^{\ddagger}(\mathbf{k J} / \mathbf{m o l})$ & $47.9 \pm 1.4$ & $26.6 \pm 1.0$ & $33.6 \pm 3.4$ \\
\hline $\boldsymbol{\Delta} \boldsymbol{S}^{\ddagger}(\mathbf{J} / \mathbf{m o l})$ & $1.57 \pm 4.8$ & $-54.3 \pm 3.2$ & $-31.6 \pm 11$ \\
\hline $\boldsymbol{\Delta} \boldsymbol{G}^{\ddagger}(\mathbf{k J} / \mathbf{m o l})$ & $47.5 \pm 1.4$ & $42.8 \pm 1.0$ & $43.0 \pm 3.4$ \\
& $\operatorname{Ln}\left(\frac{k}{T}\right)=\frac{-\Delta H^{\ddagger}}{R T}+\frac{\Delta S^{\ddagger}}{R}+\frac{\Delta C_{p}}{R} *\left\{-1+\frac{T_{0}}{T}+\operatorname{Ln}\left(\frac{T_{0}}{T}\right)\right\}+\operatorname{Ln}\left(\frac{k_{b}}{h}\right)$
\end{tabular}

Eq S1

With $k$ is the rate of proton transfer; $\mathrm{R}$ the universal gas constant; $h$ is Planck's constant; $k_{\mathrm{B}}$ the Boltzmann constant; $T_{0}$ and $\mathrm{T}$ are the reference temperature at $298 \mathrm{~K}$ and temperature, respectively; $\Delta S, \Delta H$, and $\Delta C_{p}$ are entropy, enthalpy, and heat capacity for the transition state, respectively (Sharma \& First 2009).

$\Delta G=\Delta H-T \Delta S$

Eq S2 
Lyngbya_majuscula

Nostoc punctiforme

Thermosynechococcus_elongatus

Nicotiania_tabacum

Pinus mugo

Daucus_carota

Physcomitrella patens

Marchantia_paleacea

Zea Mays

Chlamydomonas_rheinhardtii

Cyanidioschyzon merolae

Lyngbya_majuscula

Nostoc punctiforme

Thermosynechococcus_elongatus

Nicotiania tabacum

Pinus_mugo

Daucus carota

Physcomitrella_patens

Marchantia_paleacea

Zea Mays

Chlamydomonas_rheinhardtii

Cyanidioschyzon_merolae

Lyngbya_majuscula

Nostoc punctiforme

Thermosynechococcus elongatus

Nicotiania_tabacum

Pinus mugo

Daucus_carota

Physcomitrella patens

Marchantia_paleacea

Zea Mays

Chlamydomonas_rheinhardtii

Cyanidioschyzon_merolae

Lyngbya_majuscula

Nostoc punctiforme

Thermosynechococcus_elongatus

Nicotiania tabacum

Pinus mugo

Daucus carota

Physcomitrella patens

Marchantia_paleacea

Zea Mays

Chlamydomonas rheinhardtii

Cyanidioschyzon merolae

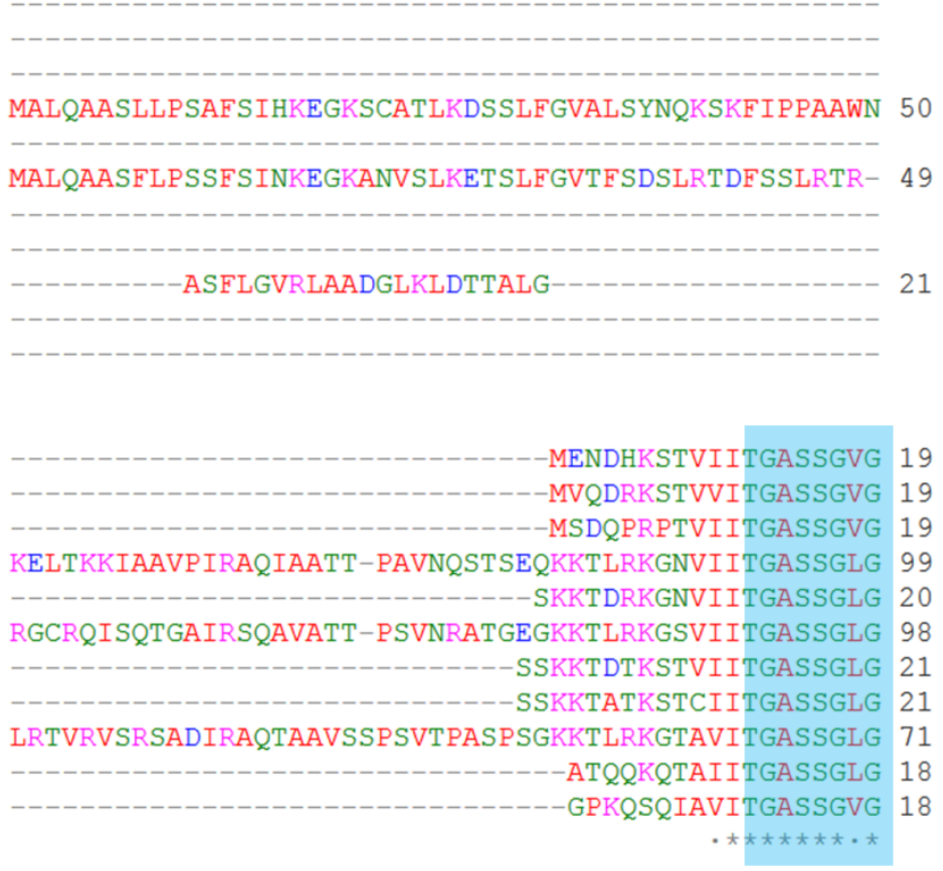

LEAARALATTWGWHVVMACRNLDKAEKAAQEVGIPKD-SYTALYIDLASF 68 LYAAKALAER-GWYVVMACRDVAKAQLAAQSVGIPHQGSYTIMHIDLGSL 68 LYATKALANR-GWHVIMACRNLEKAEQAAKNLQIPPE-AYTILHLDLSSL 67 LATAKAIGETGEWHVIMACRDFLKAEKAAKSVGIPKE-NYTVMHLDLASL 148 LATAKALGESGKWHI IMACRDFLKAERMARSVGIPKE-NYSVMHLDLASL 69 LATAKALAETGKWHVIMACRDFLKAERAAKSAGMPKE-NYTIMHLDLASL 147 LATAKVLADSGEWHVIMACRDFLKAERAAKSVGMPKE-NYTVMHCDLSSL 70 LATAKALADTGEWHVIMACRDFLKAERAARSVGIPKD-SYTVIHCDLASF 70 LATAKALAETGKWHVIMACRDFLKASRAAKAAGMDKD-SFTVVHLDLASL 120 LNAAKALAATGEWHVVMACRDFLKAEQAAKKVGMPAG-SYSILHLDLSSL 67 LYAARALVNKGNWHIVMACRDIDRAERAADSVNLPKD-AYTVLHCDLADF 67

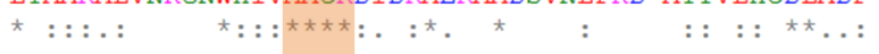

ASVRQFVNAFRATGRT--LDALVCNAAIYLPLSKEPLRNPEGYELSVATN 116 DSVRQFVKNFRASGHS--LDALVCNAAIYMPLIKEPLRSPEGYELTVTTN 116 ASVRGFVESFRALNRP--LRALVCNAAVYYPLLKEPIYSVDGYEITVATN 115 ESVRQFVDTFRRSGRP--LDALVCNAAVYLPTAKEPTFTADGFELSVGTN 196 ESVRQFADNFRRSGRP--LDVLVCNAAIYLPTAKLPTYTAEGFELSVGTN 117 DSVRQFVETFRRSERP--LDVLVCNAAVYFPTAKEPTYTADGFELSVGTN 195 NSVKQFVDNFRRSGRP--LDVLVCNAAVYLPTAKEPRYTADGFELSVGTN 118 DSVRAFVDNFRRTERQ--LDVLVCNAAVYFPTDKEPKFSAEGFELSVGTN 118 DSVRQFVRNVRQLKMP--IDVVVCNAAVYQPTAKEPSYTADGFEMSVGVN 168 ESVRQFVQNFKASGRR--LDALVCNAAVYLPTAKEPRFTADGFELSVGTN 115 ASVLKFVRELSSVARVDHLDALICNAAIWHPRDKKPRFTVDGIEETMQVC 117

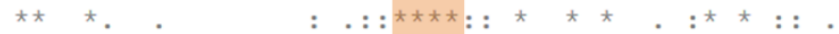


Lyngbya_majuscula Nostoc punctiforme

Thermosynechococcus_elongatus

Nicotiania_tabacum

Pinus mugo

Daucus_carota

Physcomitrella_patens

Marchantia_paleacea

Zea Mays

Chlamydomonas rheinhardtii

Cyanidioschyzon_merolae

Lyngbya_majuscula

Nostoc_punctiforme

Thermosynechococcus_elongatus

Nicotiania_tabacum

Pinus mugo

Daucus_carota

Physcomitrella patens

Marchantia_paleacea

Zea Mays

Chlamydomonas rheinhardtii

Cyanidioschyzōn_merolae

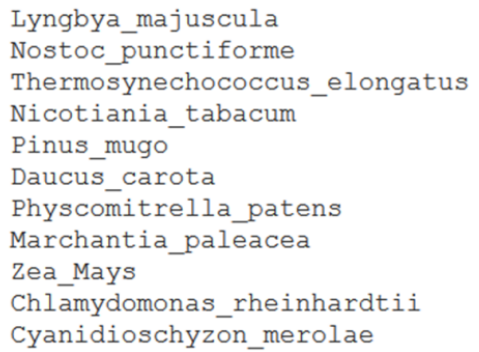

Figure S1. Alignment of the protein sequences of POR homologs using Clustal W 2.0 with important regions highlighted (Larkin et al. 2007, Goujon et al. 2010). The typical SDR coenzyme (NADPH) binding motif, TGxxxGxG, is highlighted in light blue and located near the N-terminal. The highly conserved YxxxK motif indicates the location of the active site, highlighted in purple. Other conserved regions that were found to be conserved in a study by Heyes et al. (2011) are highlighted in orange, along with the red bracket indicating 4 extra residues in the cyanobacteria PORs and Cyanidioschyzon merolae.
HLGHFLLCNLMLEDLKNSSSS-QPRLVIVGTVTANPKELGGKIPIPAPPD 165 HLGHFLLCNLMLEDLKKSSS--EPRLVILGTVTHNPDELGGKIPP--RPD 162 HLGHFLLINLLLEDLKNSPES-DKRLVILGTVTANRKELGGKIPIPAPPD 164 HLGHFLLSRLLLDDLKQSDYP-QKRLIIVGSITGNTNTLAGNVPP--KAN 243 HLGHFLLSRLLLEDLKTSDFN-SKRVIIVGSITGNTNTLAGNVPP--KAN 164 HLGHFLLSRLLLDDLNKSDYP-SKRLIIVGSITGNTNTLAGNVPP--KAN 242 HLGHFLLANLLMEDIQHKENNNSRRVIIVGSITGNTNTVAGNVPP--KAN 166 HMGHFLLARLLMEDLQKAKDS-LKRMIIVGSITGNSNTVAGNVPP--KAN 165 HLGHFLLARELLSDLQSSDYP-SKRLIIVGSITGNTNTLAGNVPP--KAN 215 HLGHFLLTNLLLDDLKNAPNK-OPRCIIVGSITGNTNTLAGNVPP--KAN 162 HLSHLLLCRELLPKLKISRG----RIVFLTTQTHSPNSLPGKIPP--QAR 161

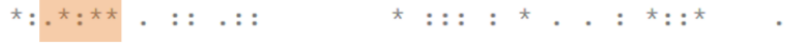

LGDLKGFEEGFKPPIS--MINGKAFKSGKAYKDSKLCNMLTMRELHHRYH 213 LGDLQGFAEGFKEPIS--MIDGKKFEPVKAYKDSKVCNVLTMRELHORYH 210 LGNLEGFEKGFKKPIA--MINGKPFKSGKAYKDSKLCNMLTARELHRRFH 212 LGDLRGLSGGLNSLNCSPMIDGGEFDGAKAYKDSKVCNMLTMQEFHRRFH 293 LGDLRGLAGGLNGVNISPMIDGGEFDGAKAYKDSKVCNMLTMQEFHRRYH 214 LGDLRGLAGGLNGMNSSAMIDGAEFDGAKAYKDSKVCNMLTMQEFHRRYH 292 LGDLRGLAGGLDGVRSSVMIDGGEFDGAKAYKDSKVCNMLTMQEMHRRFH 216 LGHLRGLAGGLNGVNSSSMIDGGEFDGAKAYKDSKVCNMFTMQEFHRRYH 215 LGDLRGLAGGLNGVGSSVMIDGGEFDGAKAYKDSKVCNMLTMQEFHRRYH 265 LGDLSGLAAGVPAAN--PMMDGQEFNGAKAYKDSKVACMMTVRQMHQRFH 210 LGDLSGLAAGLGPQTTG-MVDSGPFEPTKAYKDAKAANVLTMKALSDRYG 210

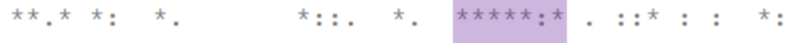

DSTGIVFSSLYPGCVAETALFRNHYSLFQ-KLFPLFQKNITKGYVSQELA 262 ESTGIVFNSLYPGCVAETPLFRNHYPLFQ-KIFPLFQKYITKGYVSQELA 259 ESTGIVFNSLYPGCVADTPLFRHHFPLFQ-KLFPLFQKKITGGYVSQELA 261 EETGIAFASLYPGCIAETGLFRNHIPLFR-ALFPPFQKYITKGYVSEAEA 342 EETGITFASLYPGCIATTGLFREHIPLFR-LLFPPFQKYITKGFVSEEEA 263 EETGITFASLYPGCIATTGLFREHIPLFR-TLFPPFOKYITKGYVSEAES 341 EKTGVTFASLYPGCIATTGLFREHYSLFR-TLFPPFQKYITKGYVSEEES 265 AETGITFSSLYPGCIAETGLFRNHVTLFR-TLFPPFQKYITKGYVSEEEA 264 EETGVTFASLYPGCIATTGLFREHIPLFR-LLFPPFOKYITKGYVSEEEA 314 DATGITFASLYPGCIAETGLFREHVPLFK-TLFPPFQKYITKGYVSEEEA 259 RD-GVTSVAIFPGCVADSNLFREKRGWFRHVFFPILQKYITRQYVPNDEA 259

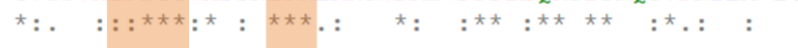

GDRLATVVADPNYNKSGVYWSWGNRQKEGRKSFVQEVSNEAMDDSKAKRL 312 GERVAAVVADPEYNQSGVYWSWGNRQKEDGKSFVQKVSPQARDDDKGDRL 309 GERVAMVVADPEFRQSGVHWSWGNRQKEGRKAFVQELSAEASDEQKARRL 311 GKRLAQVVRDPSLSKSGVYWSWNNTSS----SFENQLSKEASDAEKARKL 388 GKRLAQVVSNPSLTKSGVYWSWNNNSG----SFENQLSEEASDPEKAKKL 309 GKRLAQVVSEPSLTKSGVYWSWNKDSA----SFENQLSEEASDVEKARKV 387 GRRLAQVVSDPSMNKSGVYWSWNNQSG----SFENELSQEASDAEKAKKL 311 GKRMAQVVSDPKLSKSGVYWSWNKDSG----SFENELSEEASNPEKAKRL 310 GKRLAQVVSDPSLTKSGVYWSWNKNSA----SFENQLSEEASDADKAKKL 360 GRRLAAVISDPKLNKSGAYWSWSSTTG----SFDNQVSEEVADDSKASKL 305 GRRVAEVATQGQFSDSGSYYQWRGKYTEGREKTKPQVIEPTYEIDKADQL 309

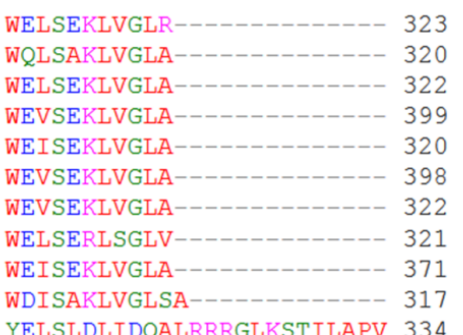



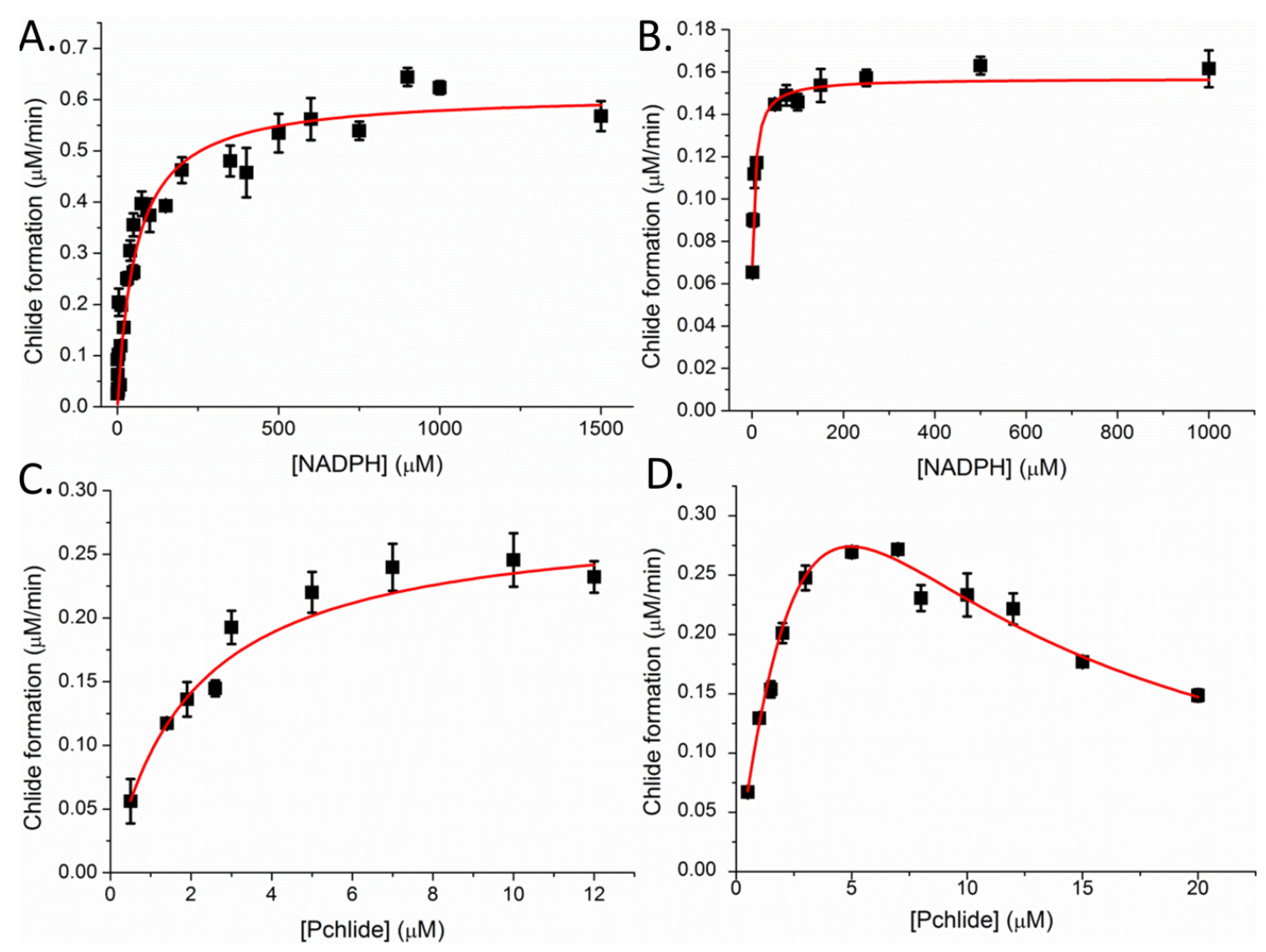

Figure S2. Examples of steady-state data used to obtain the kinetic parameters for POR homologs. Panels A and B show the dependence of the initial rate of Chlide formation on the concentration of NADPH for POR from L. majuscula (A) and N. tabacum (B). Samples contained 0.1 $\mu \mathrm{M}$ of each POR enzyme, $12 \mu \mathrm{M}$ Pchlide, $0.1 \%$ Triton X-100 and $0.1 \%$ 2-mercaptoethanol in activity buffer. Graphs were fitted to a hyperbolic equation to obtain the $V_{\max }$ and $K_{\mathrm{m}}$ for NADPH. Panels $\mathrm{C}$ and $\mathrm{D}$ show the dependence of the initial rate of Chlide formation on the concentration of Pchlide for POR from N. tabacum (C) and Z. mays (D). Samples contained $0.1 \mu \mathrm{M}$ of each POR enzyme, $200 \mu \mathrm{M}$ NADPH, $0.1 \%$ Triton X-100, $0.1 \%$ 2-mercaptoethanol in activity buffer. Graphs were fitted to a hyperbolic equation to obtain the $K_{\mathrm{m}}$ for Pchlide. All initial rates were measured by following the increase in absorbance at $670 \mathrm{~nm}$ upon illumination with a $455 \mathrm{~nm}$ LED at a fixed distance and a fixed power setting. 


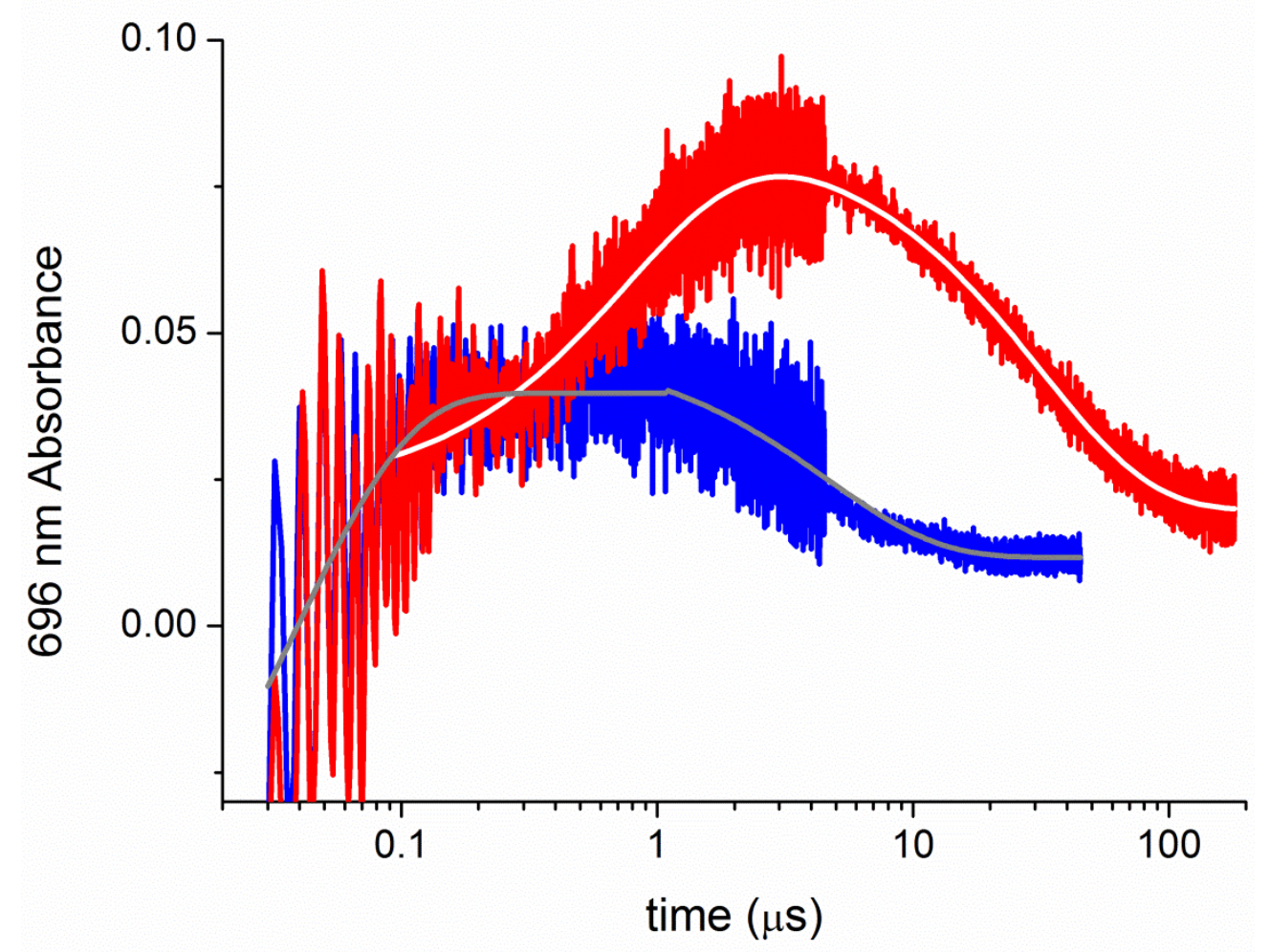

Figure S3. Representative transients showing the absorbance changes at $696 \mathrm{~nm}$ for the hydride and proton transfer steps on a log scale. The data in red are for the 'slow' cyanobacterial POR from $N$. punctiforme, while the data in blue are for a 'fast' reaction for the 'evolved' higher plant enzyme from P. mugo. Formation of an intermediate (hydride transfer) with an absorbance maximum at 696 $\mathrm{nm}$ is followed by proton transfer (decay in absorbance at $696 \mathrm{~nm}$ ) to form the Chlide product. 

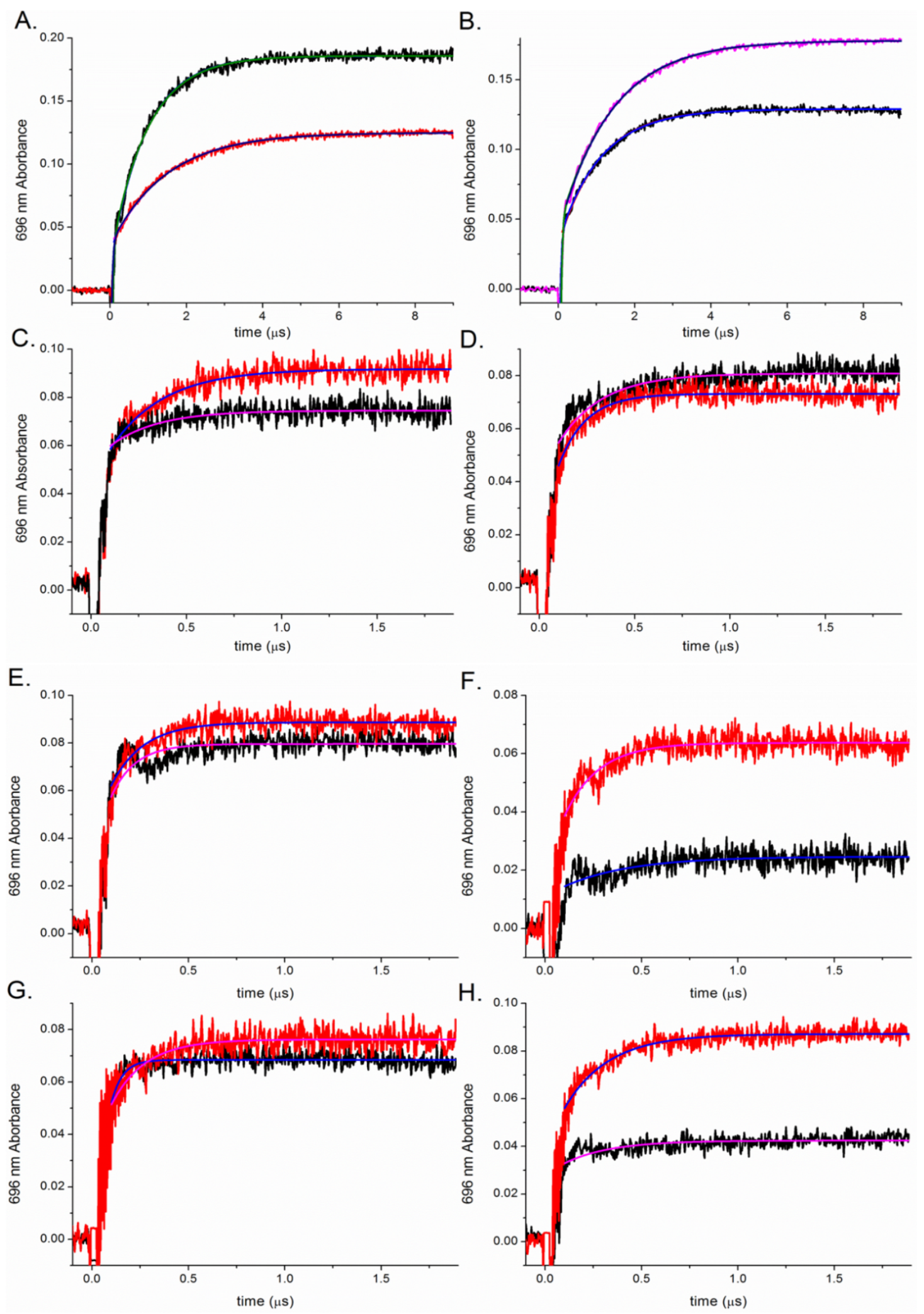

Figure S4. Transients for hydride transfer for all POR homologs at $4^{\circ} \mathrm{C}$. Samples contained 100 $\mu \mathrm{M}$ of each POR enzyme, $30 \mu \mathrm{M}$ Pchlide, $3 \mathrm{mM}$ NADPH, $0.1 \%$ Genapol and $0.1 \% 2-$ mercaptoethanol in activity buffer with $0 \%$ glycerol (black) and with $60 \%$ glycerol (red). Fitting of the data was done with both a single (blue and cyan) and a double (green and purple) exponential equation for POR from $L$. majuscula (A) and $N$. punctiforme (B). POR from $C$. reinhardtii (C), $P$. patens (D), P. mugo (E), D. carota (F), N. tabacum (G) and Z. mays (H) were fitted to a single exponential equation from approximately $100 \mathrm{~ns}$ onwards. 

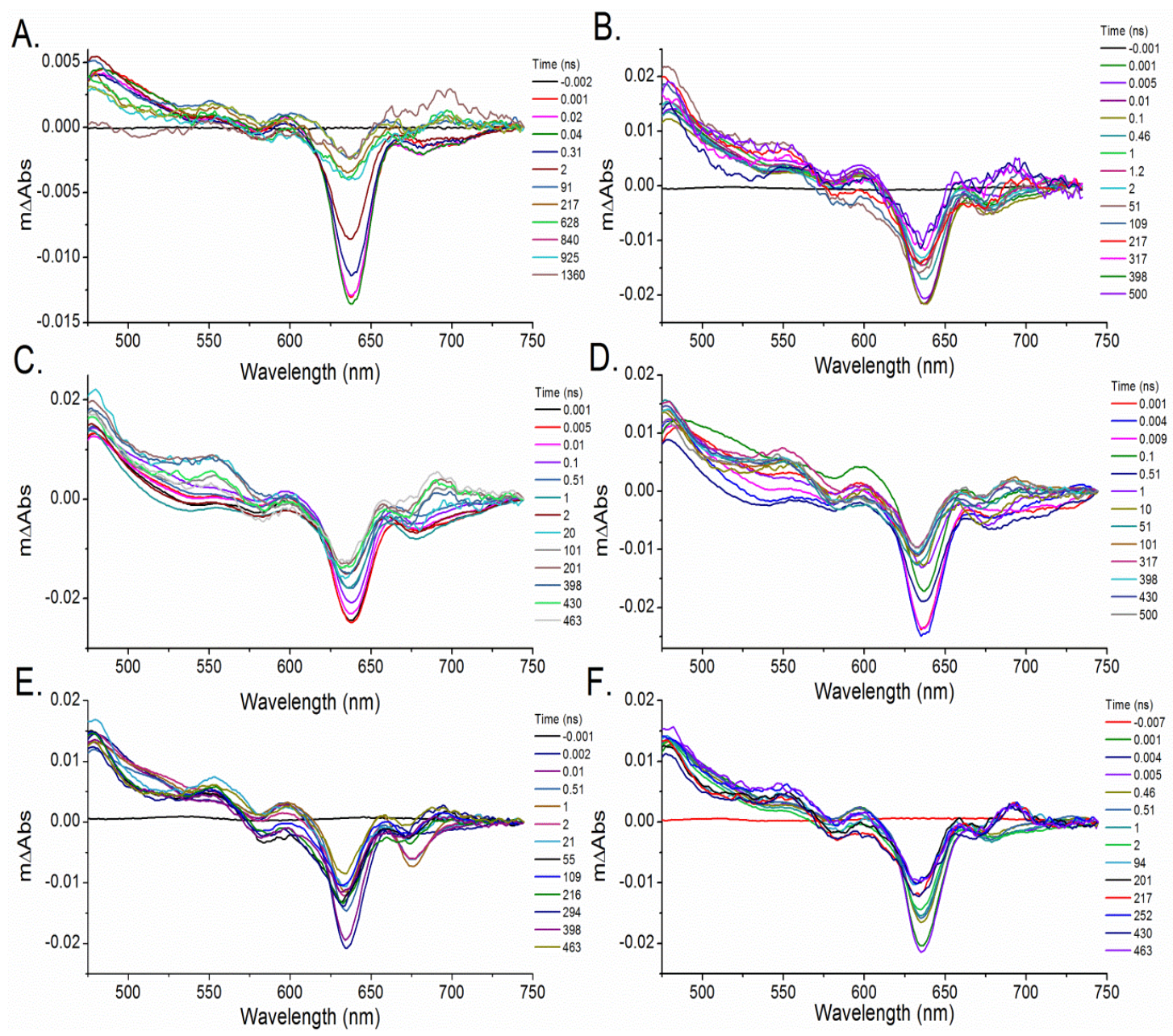

Figure S5. Time-resolved spectroscopy data for three representative POR homologues after photoexcitation with a laser pulse centred at $\sim 450 \mathbf{~ n m}$. Time-resolved difference spectra were recorded between 1 ps and $2 \mu \mathrm{s}(\mathrm{A})$ or $0.5 \mu \mathrm{s}(\mathrm{B}, \mathrm{C}, \mathrm{D}, \mathrm{E}$, and F) as described in Materials and methods for POR from $N$. punctiforme (A), C. reinhardtii (B), P. patens (C), D. carota (D), $N$. tabacum (E), and Z. mays (F). 

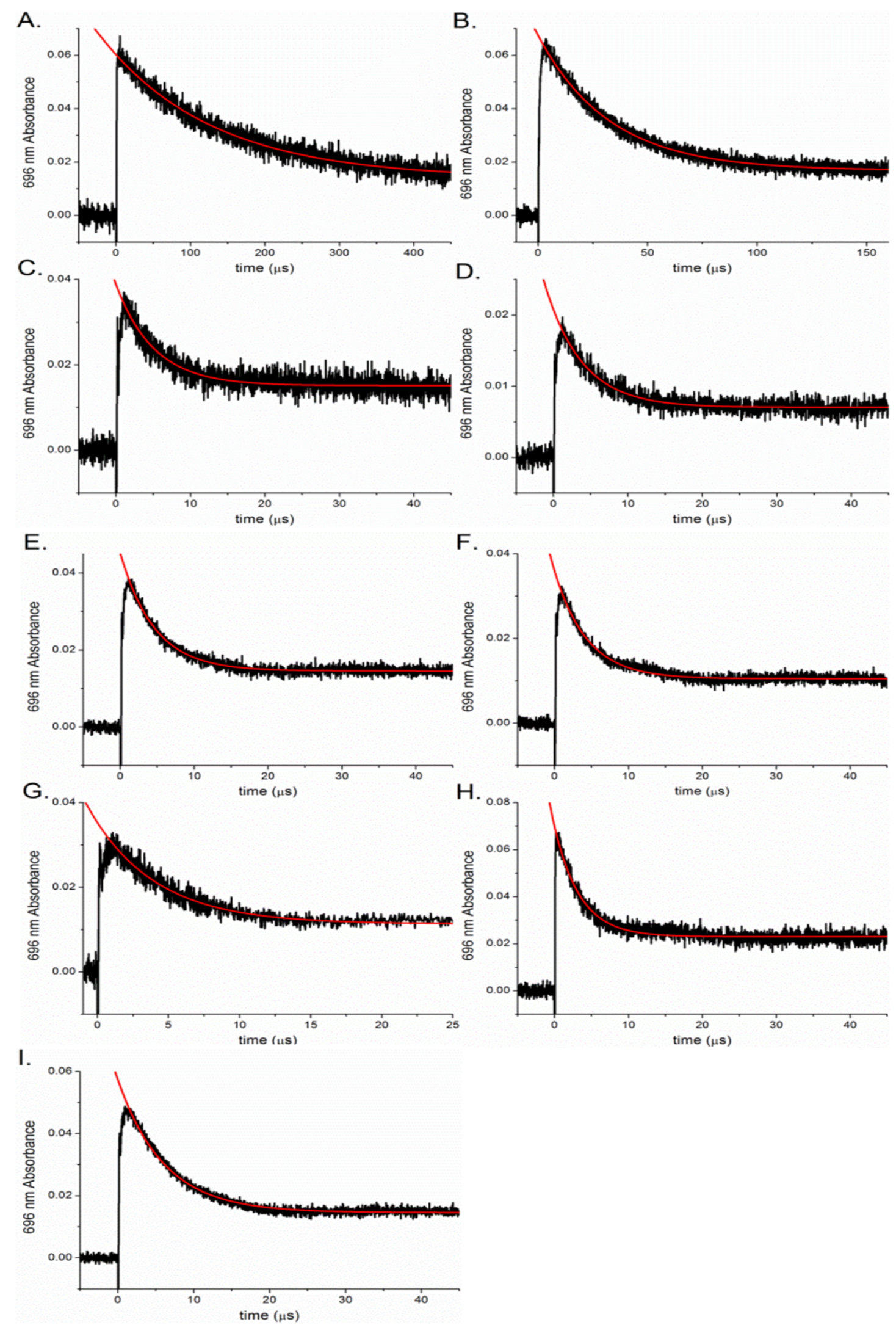

Figure S6. Transients for proton transfer for all POR homologs at $\mathbf{2 5}^{\circ} \mathrm{C}$. Samples contained 100 $\mu \mathrm{M}$ of each POR enzyme, $30 \mu \mathrm{M}$ Pchlide, $3 \mathrm{mM}$ NADPH, $0.1 \%$ Triton X-100 and $0.1 \% 2$ mercaptoethanol in activity buffer. The red lines are the single exponential fits used to calculate the rates of proton transfer (Table 5.3) for POR from L. majuscula (A), N. punctiforme (B), C. reinhardtii (C), C. merolae (D), P. patens (E), P. mugo (F), D. carota (G), N. tabacum (H) and Z. mays (I). 

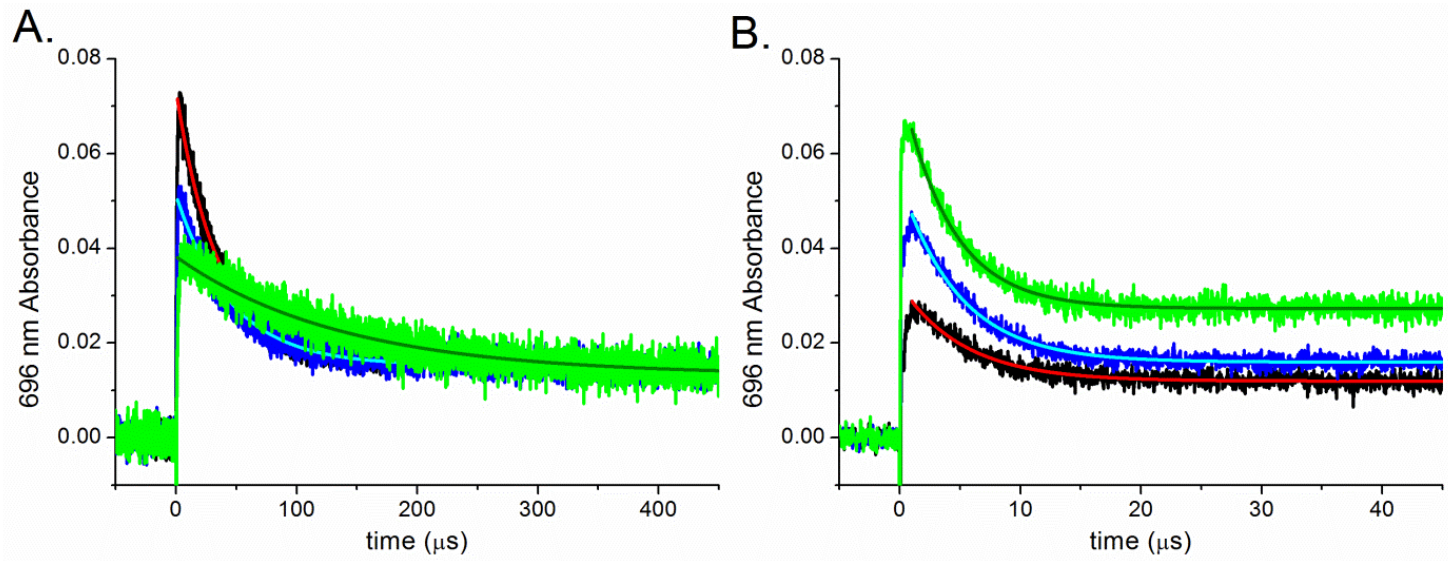

Figure

S7. Comparison of the proton transfer transients for a viscosity-dependent and viscosityindependent POR homolog. Samples contained $50 \mu \mathrm{M}$ of each POR enzyme, $15 \mu \mathrm{M}$ Pchlide, NADPH is $10 \mathrm{x}$ NADPH $K_{\mathrm{m}}$ for respective protein, $0.1 \%$ Triton X-100, $0.1 \%$ 2-mercaptoethanol in activity buffer with added glycerol to make up a solvent viscosity of $0.9 \mathrm{cP}$ (black), $1.42 \mathrm{cP}$ (blue), and $3.98 \mathrm{cP}$ (green). A Rate of proton transfer for $N$. punctiforme decreases with increase in solventviscosity. B. Rate of proton transfer for $D$. carota remains similar at all solvent-viscosities. 


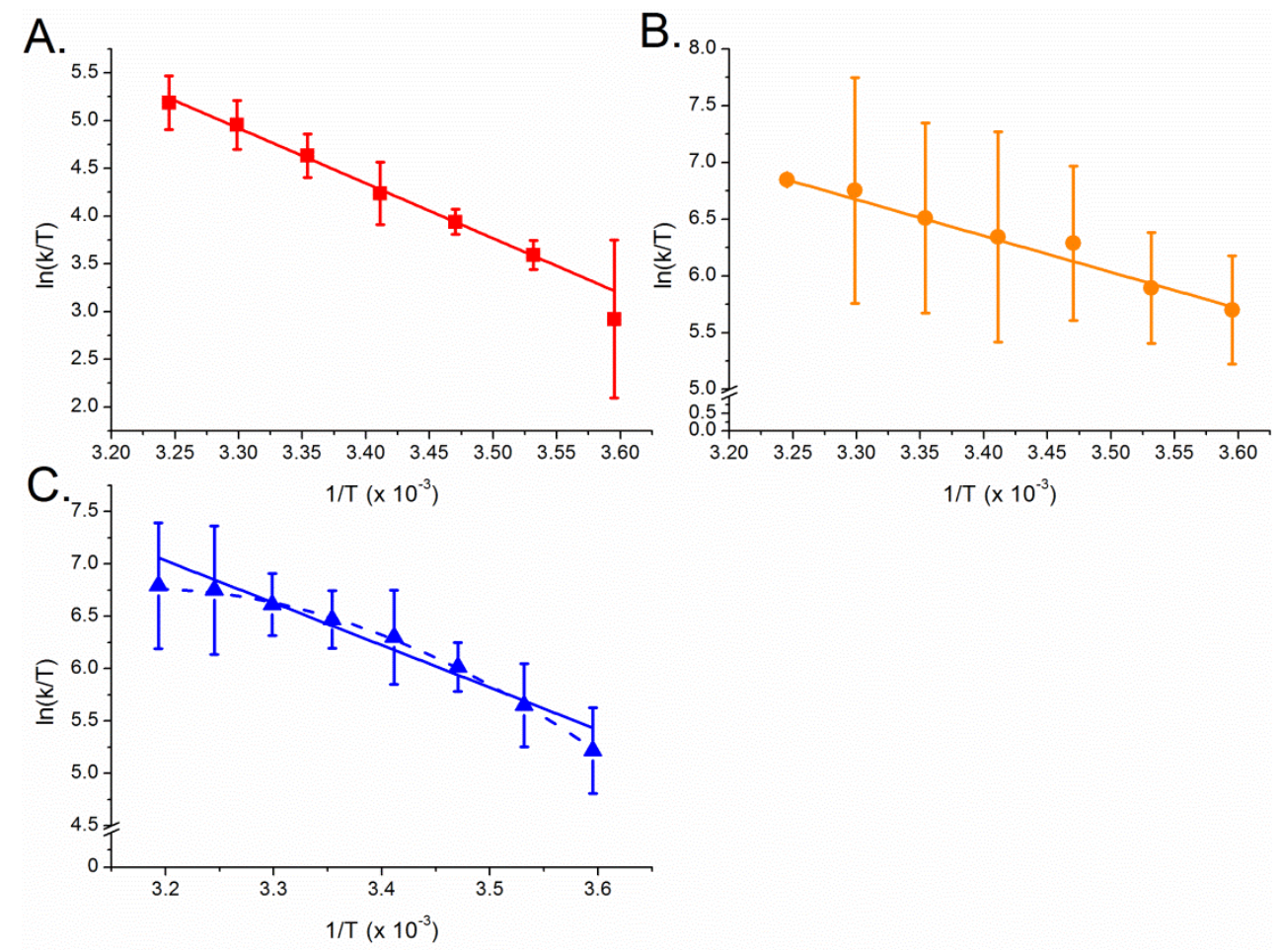

Figure S8. Temperature dependence of the rate constants for the proton transfer step for three POR homologs. Eyring plots of $\ln \left(k_{\mathrm{obs}} / \mathrm{T}\right)$ versus $1 / \mathrm{T}$ for the proton transfer step are shown for POR from the cyanobacteria $N$. punctiforme (A), the algae $C$. reinhardtii (B) and for the higher plant $Z$. mays (C). Data are shown fitted to the Eyring equation although a more accurate fit of data in graph $\mathrm{C}$ is achieved by using equation $\mathrm{S} 1$ due to the curvature of the Eyring plot. Activation enthalpies, $\Delta H^{\sharp}$, and activation entropies, $\Delta S^{\ddagger}$, are shown in table S3. Error bars are calculated from the average of at least 5 kinetic traces. 